\title{
DEMYELINATING DISEASE IN PATIENTS WITH MYASTHENIA GRAVIS
}

\author{
Denis Bernardi Bichuetti, ${ }^{1,2}$, Tatiane Martins de Barros ${ }^{1,2}$, Enedina Maria Lobato Oliveira ${ }^{1,3,5}$, \\ Marcelo Annes ${ }^{1,3}$, Alberto Alain Gabbai,
}

\begin{abstract}
Myasthenia gravis (MG) is an autoimmune disease characterized by fluctuating muscle weakness, caused by impaired neuromuscular transmission. Patients with MG can present other autoimmune diseases in association, commonly hypo or hyperthyroidism. The association of MG to demyelinating disease is rare and has been described before. We report on three Brazilian patients with MG that presented distinct demyelinating diseases, two monophasic and one recurrent neuromyelitis optica, several years after the diagnosis of MG, and discuss their clinical courses.
\end{abstract}

KEY WORDS: myasthenia gravis, demyelinating disease, association.

\section{Doenças desmielinizantes em pacientes com miastenia gravis}

Resumo - Miastenia gravis (MG) é doença autoimune caracterizada por episódios de fraqueza muscular alternados com melhora, causada por bloqueio da junção neuromuscular. Pacientes com MG podem apresentar outras doenças autoimunes, comumente hipo ou hipertiroidismo, e a associação de MG com doenças desmielinizantes é raramente descrita. Relatamos três pacientes brasileiros com MG que desenvolveram doenças desmielinizantes, dois monofásicos e um neuromielite óptica recorrente, vários anos após o diagnóstico de MG e discutimos seus cursos clínicos.

PALAVRAS-CHAVE: miastenia gravis, doenças desmielinizante, associação.

Myasthenia gravis (MG) is an autoimmune disease characterized by fluctuating muscle weakness, caused by impaired neuromuscular transmission. Autoantibodies specific for the human nicotinic acetylcholine receptor are present in 70 to $80 \%$ of the patients, and the remaining cases can be associated with antibodies targeted at muscle specific kinase (MuSK) and other proteins in the post-synaptic membrane ${ }^{1,2}$. MG has a bimodal incidence: (1) 20 to 40 years-old, predominated by women, and (2) 60 to 80 years-old, predominated by men ${ }^{2}$.

Patients with MG commonly have thyroid disease and can present with nonspecific immune system abnormalities, such as positive auto antibodies and alopecia area$\mathrm{ta}^{3-5}$. Rarely, MG can be part of multiple autoimmune syndromes, including autoimmune diabetes mellitus, thrombotic thrombocytopenic purpura, Sjögren syndrome, systemic lupus erythematosus, vitiligo, among other rare diseases ${ }^{5}$. In the past 20 years there has been an increasing number of reports on patients with MG presenting demyelinating diseases $(D D)^{6-15}$, including multiple sclerosis, neuromyelitis optica (NMO), transverse myelitis and optic neuritis. However, it is not known whether this association is also part of unspecific immune activation, genetic susceptibility or if it just happens by random.

We herein describe three Brazilian patients with MG that presented different DD and discuss their clinical courses.

\section{METHOD}

We reviewed the records of 630 patients followed for MG at the Neuroimmunology Clinic of the Federal University of Sao Paulo between 1979 and 2006. The diagnosis of MG was based on clinical history, neurological examination, electrophysiological testing and response to acetyl cholinesterase inhibitor medication (pyridostigmine), assessed by a neurologist trained in neuromuscular diseases. Rarely, patients were submitted to muscular biopsies to rule out other muscular conditions. Patients that presented with symptoms suggesting DD were selected for description. This review was approved by the Internal Review Board (\# 0498/05) as part of an analysis of all patients with MG.

Federal University of São Paulo, São Paulo SP, Brazil: 'Neurology and Neurosurgery Department; ${ }^{2}$ Post-Graduate Student of Neurology; ${ }^{3}$ Assistent Phisician; ${ }^{4}$ Full Professor, Discipline of Neurology; ${ }^{5}$ Neurologist Consultant for Bayer Schering Pharma do Brasil.

Received 3 August 2007, received in final form 14 November 2007. Accepted 10 December 2007.

Dr. Denis Bernardi Bichuetti - Rua Pedro de Toledo 377-04039-000 São Paulo SP - Brasil.E-mail: denisbichuetti@globo.com 
Table 1. Myasthenia gravis clinical data.

\begin{tabular}{cccccclc}
\hline Patient & Sex & $\begin{array}{c}\text { Age of onset } \\
\text { (years) }\end{array}$ & ENMG & $\begin{array}{c}\text { Chest } \\
\text { CT }\end{array}$ & Thymectomy & Treatment & ANA \\
\hline 1 & F & 26 & $25 \%$ & neg & yes & Pyridostigmine & neg \\
2 & M & 27 & $14.7 \%$ & neg & no & Deflazacort + cyclosporine + pyridostigmine & neg \\
3 & F & 23 & na & na & yes & Azathioprine + prednisone + pyridostigmine* & $1 / 320$ \\
\hline
\end{tabular}

na, not available; neg, negative; ANA, antinuclear antibodies; ENMG, electroneuromyography; ${ }^{*}$ patient 3 is currently under no medication due to pregnancy.

Table 2. Demyelinating disease clinical data.

\begin{tabular}{ccclll}
\hline Patient & $\begin{array}{c}\text { Age of onset } \\
\text { (years) }\end{array}$ & $\begin{array}{c}\text { Time from MG } \\
\text { to DD (years) }\end{array}$ & Presentation & Follow-up & MRI \\
\hline 1 & 32 & 6 & Ataxia, vertigo and INO & Resoled with 3g methylprednisolone & Brainstem \\
2 & 45 & 18 & ON & Resolved spontaneously & Unspecific \\
3 & 27 & 14 & Myelitis & Evolved to recurrent NMO & Myelitis C5-C7 \\
\hline
\end{tabular}

MG, myasthenia gravis; DD, demyelinating disease; INO, internuclear ophtalmoplegia; NMO, neuromyelitis optica; ON, optic neuritis.

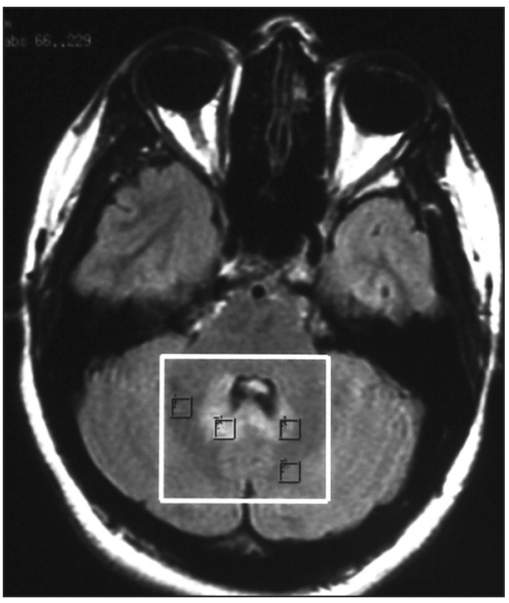

Figure. MRI of patient one after onset of symptoms. MRI FLAIR image of brainstem disclosing hyperintense signal in medial cerebellum and cerebellar peduncles, suggestive of demyelination.

\section{RESULTS}

We found three patients with MG that developed DD during follow-up; their clinical, electrophysiological and autoantibodies status are described in Tables 1 and 2. Briefly, patient 1 was diagnosed with generalized MG at the age of 26. Anti-thyroid antibodies were present (antithyroid peroxidase and anti-tireoglobulin), but she never developed thyroid disease symptoms. She underwent thymectomy one year later and evolved asymptomatic on pyridostigmine treatment, thymus pathology disclosed lymphoid hyperplasia. At age 32, she presented mild truncal and gait ataxia associated to bilateral horizontal nystagmus. Brain magnetic resonance imaging (MRI) disclosed pons and cerebellum FLAIR and T2 hyperintense signal and mild gadolinium enhancement compatible with demyelination (Figure), cerebro-spinal fluid was normal. She was treated with $3 \mathrm{~g}$ IV methylprednisolone and symptoms resolved completely. MRI follow-up images disclosed resolution of the preview lesion and no new T2 or FLAIR ab- normalities. She is currently on pyridostigmine for symptomatic myasthenia control.

Patient 2 had intermittent diplopia since the age of 27 and was further diagnosed with ocular myasthenia. He was initially treated with prednisone and pyridostigmine with mild response to treatment. Prednisone was switched to azathioprine due to hypertension, but symptoms only resolved when cyclosporine was started. At age 45 he developed pain, low visual acuity and ptosis in the left eye. Fundoscopic examination revealed a swollen disc on the left eye. MRI of the brain disclosed small unspecific periventricular and subcortical white matter changes on T2 and FLAIR sequences. Cyclosporine dose was raised and deflazacort introduced for symptomatic treatment of ptosis. Symptoms resolved completely and his visual acuity returned to normal 2 months later.

Patient 3 was diagnosed with generalized MG at the age of 27 and underwent thymectomy one year after diagnosis. Four years later she presented with left side paresthesias and her spinal cord MRI disclosed a demyelinating lesion from $\mathrm{C} 5$ to $\mathrm{C}$, absent cerebrospinal fluid oligoclonal bands and normal brain MRI. Symptoms resolved after 3 g IV methylprednisolone. Two months later she developed bilateral acute visual loss that resolved within 30 days. On first evaluation she had an atrophic optic disc on the left side, mild spastic gait and increased muscle stretch reflexes. A clinical diagnosis of neuromyelitis optica was made based on the Wingerchuck criteria ${ }^{16}$ and she was started on azathioprine plus prednisone. During the next 2 years she presented with 1 myelitis and 2 optic neuritis relapses, treated with IV methylprednisolone. Ancillary test revealed an anti-nuclear-antibody (ANA) titer of $1 / 320$. She recently became pregnant and stopped her medication, but her neurological exam discloses only mild 
low visual acuity without fatigue. Data from her thymectomy was unavailable from the other hospital.

\section{DISCUSSION}

We report on a series of Brazilian patients that presented distinct DD 6-18 years after the diagnosis of MG. Two of them presented a monophasic course (patients 1 and 2), one evolved to recurrent neuromyelitis optica (patient 3). The occurrence of DD in association to MG have been reported before, and are described as monophasic events (myelitis, acute disseminated encephalomyelitis and optic neuritis) 10-13 $^{13}$ and recurrent diseases (multiple sclerosis, recurrent transverse myelitis and NMO) ${ }^{7,-12,14}$. Some authors state that this association may not happen by chance, as the incidence of DD in patients with MG is much higher than expected in the general population ${ }^{6,15}$, and both may be part of multiple autoimmune syndromes or genetic predisposition to autoimmunity ${ }^{5}$.

Recently, two reports have focused on this association. Gotkine et al. ${ }^{10}$ reported on 5 patients that presented DD after the diagnosis of MG, three had a monophasic event and two had a recurrent illness. The authors suggest that the association might be caused by subclinical systemic lupus erythematosus in three of them due to the presence of antinuclear antibodies, including both cases with recurrent $D D$, although this has been contested due to the fact that two of their patients could actually have $\mathrm{NMO}^{16-18}$. Kister et al. ${ }^{9}$ report on 4 patients that presented recurrent NMO years after undergoing thymectomy for MG. Two of these patients were positive for NMO-Ig antibodies in their serum ${ }^{18}$ and ANA and anti-GAD were also present in 3 patients, disclosing systemic immune abnormalities. In both series, as in other cases reported before ${ }^{7,12-15}$ patients developed DD years after undergoing thymectomy, and the authors suggest that thymectomy might have induced immune dysregulation. Indeed, a long-term study of thymectomized patients showed that a significant number of patients presented different autoantibodies in their serum years after thymectomy, $43 \%$ developed ANA positivity, $12.5 \%$ of them developed autoimmune diseases, and more than $60 \%$ had at least 1 expansion within the CD8 and CD4 T-cell repertoire, compared with non-thymectomized patients and healthy control subjects ${ }^{19}$.

Two of our patients have undergone thymectomy and only one presented positive ANA (patient 3); interestingly, this was the only one that evolved to a recurrent DD. This patient resembles those reported by Kister et al. ${ }^{9}$, who suggested that unspecific immune dysregulation, either due to thymectomy or genetic susceptibility might influence the development of a second autoimmune disease. Although all our patients achieved a good control of myasthenia symptoms, we could not determine the influence of developing DD on MG control due to the small number of patients in this series. Furthermore, in our service only 3 out of 630 patients with MG developed DD (0,5\%), much less than the rate observed by Gotkine et al.. ${ }^{10}$. While we evaluated 630 ambulatory patients, Gotkine et al surveyed 214 patients that were admitted to the hospital, which does not reflect the whole population of patients with MG in a tertiary care center. This methodological difference may have left to selection bias of more severe patients, among them those with DD.

In conclusion, demyelinating diseases are rare among patients with MG and may be part of an autoimmune syndrome spectra or genetic predisposition to autoimmunity. In this series of patients, only one developed a relapsing-remitting disease with positive low titer ANA and the others presented a monophasic course. As this is a small retrospective series, it was not possible to determine whether DD was related to thymectomy and its potential impact on myasthenia gravis clinical control.

\section{REFERENCES}

1. Vincent A, Palace J, Hilton-Jones D. Myasthenia gravis. Lancet 2001, 357:2122-2128.

2. Romi F, Gilhus NE, Aarli JA. Myasthenia gravis: clinical, immunological, and therapeutic advances. Acta Neurol Scand 2005;111:134-141.

3. Kiessling WR, Pflughaupt KW, Ricker K, Haubitz I, Mertens HG. Thyroid function and circulating antithyroid antibodies in myasthenia gravis. Neurology 1981;31:771-774.

4. Suzuki S, Shimoda M, Kawamura M, et al. Myasthenia gravis accompanied by alopecia areata: clinical and immunogenetic aspects. Eur J Neurol 2005;12:566-570.

5. Meyer O. [Immunogenetics in the understanding of multiple autoimmune syndromes]. Ann Med Interne (Paris) 1988;139:155-158.

6. Keesey JC. Does myasthenia gravis affect the brain? J Neurol Sci 1999; 170:77-89.

7. Furukawa Y, Yoshikawa H, Yachie A, Yamada M. Neuromyelitis optica associated with myasthenia gravis: characteristic phenotype in Japanese population. Eur J Neurol 2006;13:655-658.

8. Achari AN, Trontelj JV, Campos DJ. Multiple sclerosis and myasthenia gravis: a case report with single fiber electromyography. Neurology 1976;26:544-546.

9. Kister I, Gulati S, Boz C, et al. Neuromyelitis optica in patients with myasthenia gravis who underwent thymectomy. Arch Neurol 2006;63:851-856.

10. Gotkine M, Fellig Y, Abramsky O. Occurrence of CNS demyelinating disease in patients with myasthenia gravis. Neurology 2006;67:881-883.

11. Aita JF, Snyder DH, Reichl W. Myasthenia gravis and multiple sclerosis: an unusual combination of diseases. Neurology 1974;24:72-75.

12. Lindsey JW, Albers GW, Steinman L. Recurrent transverse myelitis, myasthenia gravis, and autoantibodies. Ann Neurol 1992;32:407-409.

13. Goldman M, Herode A, Borenstein S, Zanen A. Optic neuritis, transverse myelitis, and anti-DNA antibodies nine years after thymectomy for myasthenia gravis. Arthritis Rheum 1984;27:701-703.

14. Mapelli G, De Palma P, Franco F, Fini M. Myasthenia gravis and recurrent retrobulbar optic neuritis: an unusual combination of diseases. Ophthalmologica 1986;192:234-237.

15. Isbister CM, Mackenzie PJ, Anderson D, Wade NK, Oger J. Co-occurrence of multiple sclerosis and myasthenia gravis in British Columbia. Mult Scler 2003;9:550-553.

16. Ikeda K, Araki Y, Iwasaki Y. Occurrence of CNS demyelinating disease in patients with myasthenia gravis. Neurology 2007;68:1326.

17. Kister I, Herbert J, Swerdlow ML, Bergamaschi R, Piccolo G, Oger J. Occurrence of CNS demyelinating disease in patients with myasthenia gravis. Neurology 2007;68:1326-1327.

18. Weinshenker BG, Jacob A. Occurrence of CNS demyelinating disease in patients with myasthenia gravis. Neurology 2007;68:1326.

19. Gerli R, Paganelli R, Cossarizza A, et al. Long-term immunologic effects of thymectomy in patients with myasthenia gravis. J Allergy Clin Immunol 1999;103:865-872. 